\title{
Soroepidemiologia da hepatite B e C em índios Kaingang do Sul do Brasil
}

\author{
Aline Ferreira, ${ }^{1}$ Daniel Greca, ${ }^{1}$ Ery Tavares, ${ }^{1}$ Yatiyo Moriya, ${ }^{2}$ \\ Florise Spelling, ${ }^{2}$ Maristela Boeira, ${ }^{3}$ Sidneis dos Santos ${ }^{4}$ \\ e lara de Messias-Reason ${ }^{1}$
}

Como citar Ferreira A, Greca D, Tavares E, Moriya Y, Spelling F, Boeira M, et al. Soroepidemiologia da hepatite B e C em índios Kaingang do Sul do Brasil. Rev Panam Salud Publica. 2006;20(4):230-5.

RESUMO Objetivo. Investigar a prevalência de infecção pelo vírus da hepatite B e C na população indígena Kaingang da reserva de Mangueirinha, no Estado do Paraná, Brasil.

Método. A presença dos marcadores sorológicos anti-HBc, anti-HBs, AgHBs e anti-VHC foi investigada em amostras de sangue de 214 voluntários (81 do sexo masculino e 133 do sexo feminino) usando técnicas imunoenzimáticas. Os participantes responderam a um questionário sobre os aspectos sociodemográficos, as condições de vida, os hábitos e o histórico de doenças e de vacinação.

Resultados. A média de idade foi de 29,85 anos (1 a 90 anos). Foi observada uma positividade de $71,02 \%$ para o marcador anti-HBs e de 15,42\% para o anti-HBc. Nenhum caso foi positivo para o marcador AgHBs. Somente um participante, uma mulher de 30 anos, apresentou positividade para anti-VHC.

Conclusão. Os resultados mostram baixa prevalência de infecção pelo VHB e pelo VHC na população Kaingang estudada. A alta prevalência de anti-HBs nas faixas etárias mais baixas indica uma boa abrangência da imunização ativa artificial. Na população adulta, é provável que a imunidade contra o VHB tenha sido adquirida principalmente de forma natural, pelo contato com o vírus.

Palavras-chave Brasil, hepatite B/epidemiologia, hepatite C/epidemiologia, saúde da população indígena.

A população indígena no Brasil é estimada em aproximadamente 400000

1 Universidade Federal do Paraná, Hospital de Clínicas, Departamento de Patologia Médica, Laboratório de Imunopatologia, Curitiba (PR), Brasil. Enviar correspondência para Iara de Messias-Reason no seguinte endereço: Rua Padre Camargo 280, CEP 80069-900, Curitiba, PR, Brasil. Fone: +55-413360-1800/ramal 6523; e-mail: iaramessias@yahoo. com.br

2 Laboratório Central do Estado do Paraná, Laboratório de Imunologia, Curitiba (PR), Brasil.

3 Unidade de Saúde da Reserva Indígena de Mangueirinha, Mangueirinha (PR), Brasil.

4 Universidade Estadual do Oeste do Paraná, Cascavel (PR), Brasil. pessoas, que perfazem cerca de $0,2 \%$ da população brasileira (1). As condições sanitárias e nutricionais precárias, assim como o contato com populações não-nativas, levaram à adoção de novas práticas culturais por parte dos indígenas brasileiros, assim como a uma maior exposição desses povos às doenças infecciosas (2-4).

$A$ infecção pelo vírus da hepatite $B$ (VHB) pode ser apontada como uma das mais importantes viroses do gênero humano. Estima-se que cerca de
300 milhões de pessoas em todo o mundo sejam portadoras do VHB, e que de 1 a 2 milhões de mortes a cada ano estejam relacionadas diretamente a esse agente (5-7). Embora a grande maioria das pessoas se recupere da infecção pelo $\mathrm{VHB}$, cerca de $10 \%$ dos indivíduos infectados podem se tornar portadores crônicos, que podem ser assintomáticos ou evoluir para doenças hepáticas graves, como cirrose ou hepatocarcinoma (8). A transmissão do VHB se faz pelo contato com san- 
gue ou líquidos corporais, tais como sêmen, secreções vaginais e saliva de indivíduos portadores do vírus, sendo o contato sexual uma das principais vias de sua propagação. No Brasil, estima-se que $15 \%$ da população já tenham entrado em contato com o VHB e que $1 \%$ sejam portadores crônicos do vírus (9).

Os marcadores sorológicos do VHB são uma importante ferramenta para o diagnóstico da hepatite $\mathrm{B}$. $\mathrm{O}$ antígeno de superfície AgHBs é o primeiro marcador a aparecer. A sua persistência no soro por 6 meses ou mais caracteriza o estado de portador do vírus, porém não indica replicação de vírions completos, podendo o indivíduo estar assintomático e livre de lesão hepática (8). A persistência na circulação dos antígenos $\mathrm{HBs}$ e $\mathrm{HBe}$, dos anticorpos contra o antígeno core do VHB (anti$\mathrm{HBc}$ ) e, algumas vezes, de anticorpos contra o antígeno de superfície (antiHBs), além do ADN viral, representa replicação crônica do $\mathrm{VHB}$, que pode ser acompanhada de lesão hepática progressiva $(7,8)$. Estudos recentes sobre a soroprevalência de hepatite B no Brasil apontam maior endemicidade na Região Norte e em áreas dos estados do Espírito Santo, Paraná e Santa Catarina (9).

Por sua vez, o vírus da hepatite $\mathrm{C}$ (VHC) é causa importante de doença hepática em todo o mundo, sendo que a principal via de transmissão é parenteral (inoculação e transfusões sangüíneas). A infecção pelo VHC apresenta alta taxa de progressão para doença crônica ou cirrose subseqüente, excedendo $50 \%$ dos casos $(8,10,11)$. O ARN viral é detectável no sangue por 1 a 3 semanas, coincidindo com as elevações das transaminases séricas, e persiste em muitos pacientes a despeito da presença de anticorpos neutralizantes. Segundo dados da Agência Nacional de Vigilância Sanitária (ANVISA), a prevalência para marcadores do VHC no Brasil é estimada em 1,0 a 2,5\%. Na Região Sul, a prevalência de marcadores do VHC em doadores de sangue é de 0,5\% (12).

Muitos estudos soroepidemiológicos têm demonstrado o caráter endêmico de diferentes doenças infecciosas em populações indígenas brasileiras $(4,10,13-16)$. Contudo, a grande maioria desses estudos se concentra em populações indígenas da Região Amazônica, onde é relatada uma alta prevalência de infecção pelo VHB. Os poucos estudos existentes em indígenas de outras regiões do Brasil revelaram baixa positividade de infecção por esse vírus $(17,18)$. Por outro lado, análises sobre a infecção pelo VHC demonstraram que essa é pouco prevalente entre ameríndios de todo $\mathrm{o}$ território brasileiro $(14,17,18)$.

O objetivo deste estudo foi determinar a prevalência de infecções por VHB e VHC na população indígena Kaingang da reserva de Mangueirinha, no Estado do Paraná, Sul do Brasil.

\section{CASUÍSTICA E MÉTODOS}

O presente projeto foi aprovado pelo comitê de ética do Conselho Nacional de Pesquisa (CONEP), pela Fundação Nacional do Índio (FUNAI) e pelos líderes locais da tribo. Foram avaliados, através de participação voluntária, 214 indivíduos Kaingang moradores da Reserva Indígena de Mangueirinha, Paraná, com idade entre 1 e 90 anos (média de 29,85 anos) e que apresentavam bom estado geral de saúde no momento da avaliação. A população dessa reserva é constituída por 1617 índios Kaingang, Guarani e Xetá distribuídos em seis aldeias (19). A tabela 1 mostra a distribuição dos participantes de acordo com a idade, $\mathrm{o}$ sexo e a presença de miscigenação com população não-indígena.

Cada participante respondeu a um questionário sobre os aspectos sociodemográficos, as condições e os hábitos de vida, a história mórbida pregressa e o histórico vacinal. No caso das crianças, os questionários foram respondidos pelos pais ou responsáveis. Os questionários foram preenchidos pelos pesquisadores, autores do trabalho. Para a obtenção de soro, de cada indivíduo foi coletada uma amostra de $10 \mathrm{~mL}$ de sangue venoso em tubo de ensaio sem anticoagulante. As amostras foram centrifugadas a $2000 \mathrm{rpm}$ por 10 minutos, aliquotadas em microtubos e armazenadas $\mathrm{a}-20^{\circ} \mathrm{C}$ até a sua utilização.

Os exames para detecção dos marcadores sorológicos AgHbs, anti-HBc (IgG e IgM), anti-HBs e anti-VHC foram realizados no Laboratório Central do Estado do Paraná (LACEN-PR), através de técnicas imunoenzimáticas, utilizando-se kits comerciais. A hepatite B foi investigada pela determinação quantitativa do anticorpo anti-HBs, utilizando-se o kit AxSYM AUSAB (Abbott, IL, EUA), pela determinação qualitativa do anticorpo anti$\mathrm{HBc}$, através do kit AxSYM CORE (Abbott), e pela determinação qualitativa do antígeno AgHbs, através do kit AxSYM AgHbs (V2) (Abbott). Todas as determinações foram feitas através de ensaio imunoenzimático de micropartículas (MEIA). Os anticorpos antiVHC (contra-seqüências do núcleo e regiões NS3, NS4 e NS5) foram investigados utilizando-se MEIA, através do kit AxSYM HCV 3.0 (Abbott). As

TABELA 1. Dados demográficos e miscigenação da população indígena Kaingang, reserva de Mangueirinha (PR), Brasil

\begin{tabular}{|c|c|c|c|c|}
\hline \multirow{2}{*}{$\begin{array}{l}\text { Idade } \\
\text { (anos) }\end{array}$} & \multicolumn{2}{|c|}{ Sexo } & \multirow[b]{2}{*}{ Total (\%) } & \multirow{2}{*}{$\begin{array}{c}\text { Miscigenação com } \\
\text { branco (\%) }\end{array}$} \\
\hline & Masculino (\%) & Feminino (\%) & & \\
\hline 01 a 10 & $14(6,54)$ & $17(7,94)$ & $31(14,48)$ & $13(6,07)$ \\
\hline 11 a 20 & $22(10,28)$ & $33(15,42)$ & $55(25,70)$ & $19(8,87)$ \\
\hline 21 a 30 & $11(5,14)$ & $23(10,74)$ & $34(15,88)$ & $6(2,80)$ \\
\hline 31 a 40 & $18(8,41)$ & $28(13,08)$ & $46(21,49)$ & $17(7,94)$ \\
\hline 41 a 50 & $4(1,87)$ & $8(3,74)$ & $12(5,60)$ & $4(1,87)$ \\
\hline 51 a 60 & $5(2,33)$ & $12(5,60)$ & $17(7,94)$ & $1(0,46)$ \\
\hline$>60$ & $7(3,27)$ & $12(5,60)$ & $19(8,87)$ & $5(2,33)$ \\
\hline Total & $81(37,85)$ & $133(62,15)$ & $214(100,0)$ & $64(29,90)$ \\
\hline
\end{tabular}


amostras não conclusivas para marcadores sorológicos do VHC, utilizandose MEIA, foram testadas para a presença de ARN viral através de técnica de reação em cadeia da polimerase (PCR), utilizando-se o kit AmplicorHepatitis C Virus Test, versão 2.0 (Roche, Branchburg, EUA).

\section{RESULTADOS}

Na população em estudo, composta por 214 índios Kaingang, houve um predomínio do sexo feminino $(62,15 \%$ vs. $37,85 \%)$. A faixa etária predominante foi de 11 a 20 anos $(25,70 \%)$. A miscigenação com população nãoindígena foi observada em $29,90 \%$ dos indivíduos (tabela 1). Conforme o questionário respondido pelos participantes, a ocupação mais freqüente foi a de dona-de-casa, declarada por $35,98 \%$ dos entrevistados, seguida por $25,70 \%$ de estudantes, $16,82 \%$ de agricultores, $8,41 \%$ de outras profissões e 13,08\% de não declarados. Em relação ao número de parceiros, $44,86 \%$ afirmaram relação com um parceiro; $10,74 \%$ com dois parceiros; $9,81 \%$ com três ou mais parceiros e $34,58 \%$ não responderam à pergunta. No que diz respeito à medicação por via parenteral, $64,95 \%$ afirmaram que já haviam recebido essa forma de tratamento alguma vez e 3,74\% referiram já ter recebido transfusão sanguínea. Quanto aos sinais clínicos, 22,89\% disseram já ter apresentado quadro de icterícia. Em relação aos hábitos de vida, $26,17 \%$ dos entrevistados afirmaram tabagismo, $1,40 \%$ etilismo e $0,93 \%$ uso de drogas ilícitas.

$\mathrm{Na}$ análise dos marcadores sorológicos para hepatite $B$, nenhuma positividade para $\mathrm{AgHbs}$ foi observada. Por sua vez, o marcador anti-HBs foi encontrado em $71,02 \%$ e o anti-HBc em $15,42 \%$ dos indivíduos. Os marcadores anti-HBs e anti-HBc foram encontrados concomitantemente em 13,55\% dos indivíduos.

A distribuição do marcador antiHBs, que representa imunidade contra o VHB (adquirida por meio de vacinação ou por contato prévio), foi variável nas diferentes faixas etárias,

TABELA 2. Prevalência de anticorpos anti-HBs e anti-HBc na população indígena Kaingang da reserva de Mangueirinha (PR), Brasil, conforme o sexo e a idade ${ }^{\mathrm{a}}$

\begin{tabular}{lrrrrr}
\hline & \multicolumn{2}{c}{ Anti-HBs } & & \multicolumn{2}{c}{ Anti-HBc } \\
\cline { 2 - 3 } \cline { 6 - 6 } $\begin{array}{l}\text { Idade } \\
\text { (anos) }\end{array}$ & $\begin{array}{c}\text { Sexo } \\
\text { masculino }(\%)\end{array}$ & $\begin{array}{c}\text { Sexo } \\
\text { feminino }(\%)\end{array}$ & & $\begin{array}{c}\text { Sexo } \\
\text { masculino }(\%)\end{array}$ & $\begin{array}{c}\text { Sexo } \\
\text { feminino }(\%)\end{array}$ \\
\hline 1 a 10 & $12 / 14(85,71)$ & $13 / 17(76,47)$ & & $0 / 14(0)$ & $0 / 17(0)$ \\
11 a 20 & $16 / 22(72,72)$ & $30 / 33(90,90)$ & & $0 / 22(0)$ & $1 / 33(3,03)$ \\
21 a 30 & $6 / 11(54,54)$ & $17 / 23(73,91)$ & & $2 / 11(18,18)$ & $4 / 23(17,39)$ \\
31 a 40 & $11 / 18(61,11)$ & $19 / 28(67,85)$ & & $5 / 18(27,77)$ & $7 / 28(25,0)$ \\
41 a 50 & $4 / 4(100,0)$ & $6 / 8(75,0)$ & & $2 / 4(50,0)$ & $4 / 8(50,0)$ \\
51 a 60 & $3 / 5(60,0)$ & $7 / 12(58,33)$ & & $1 / 5(20,0)$ & $1 / 12(8,33)$ \\
$>60$ & $4 / 7(57,14)$ & $4 / 12(33,33)$ & & $4 / 7(57,14)$ & $2 / 12(16,66)$ \\
\hline
\end{tabular}

a Total de 81 indivíduos do sexo masculino e 133 do sexo feminino.

como pode ser observado na tabela $2 \mathrm{e}$ na figura 1. Por outro lado, a presença do marcador anti-HBc, que indica contato prévio com o $\mathrm{VHB}$, apresentou um gradiente de positividade crescente em relação à idade. Entre os 33 indivíduos que apresentaram infecção prévia pelo VHB, 39,39\% relataram história de icterícia, 9,09\% mencionaram transfusão sangüínea anterior e 9,09\% afirmaram relação sexual com múltiplos parceiros. Nos demais casos, não foi possível estabelecer uma provável causa de aquisição da infecção.

O marcador sorológico para hepatite C (anti-VHC) foi positivo somente em um participante, uma mulher de 30 anos $(0,46 \%)$. A ausência de positivi-

FIGURA 1. Distribuição da prevalência de anticorpos anti-HBs e anti-HBc na população indígena Kaingang da reserva de Mangueirinha (PR), Brasil, de acordo com a idade

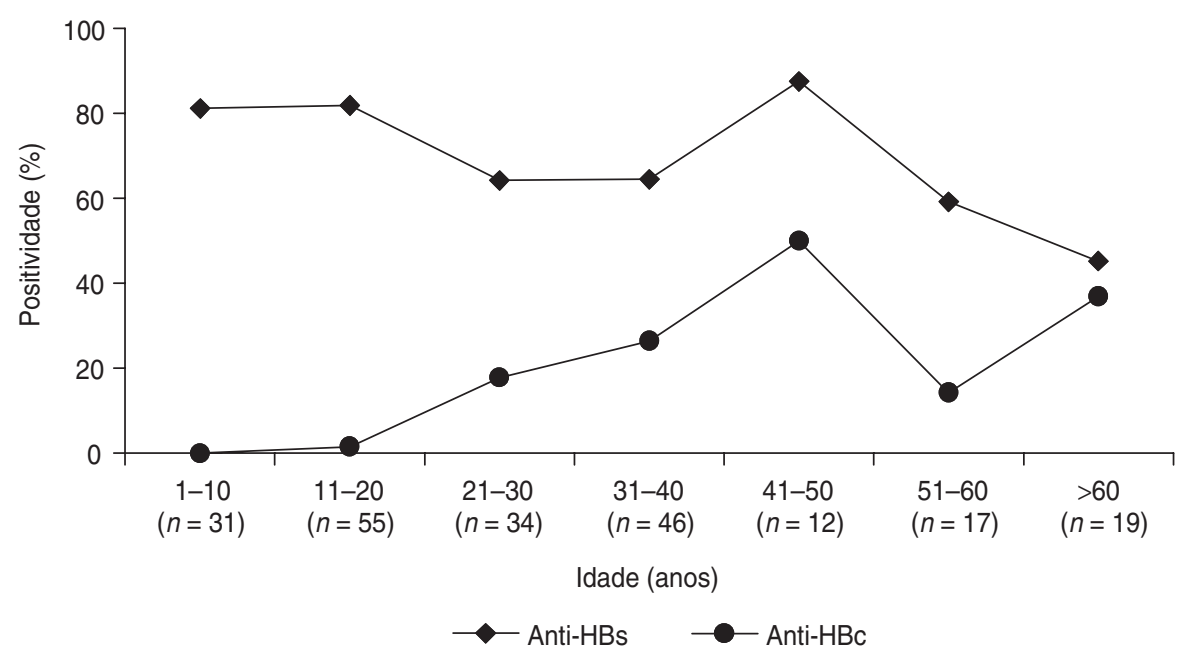

dade para todos os marcadores investigados ocorreu em $26,63 \%$ dos indivíduos, indicando ausência de contato prévio ou vacinação contra o VHB. A figura 2 mostra a prevalência de marcadores de hepatite $\mathrm{B}$ e $\mathrm{C}$ na presente população e em diferentes populações indígenas brasileiras.

\section{DISCUSSÃO}

Os estudos soroepidemiológicos permitem avaliar peculiaridades de diferentes populações, nas quais valores e práticas culturais distintos podem afetar o processo de saúde e doença. Atualmente, a população indígena bra- 
FIGURA 2. Prevalência dos marcadores de hepatite B e C (AgHBs, anti-HBs, anti-HBc e antiVHC) em diferentes populações indígenas brasileiras ${ }^{a}$

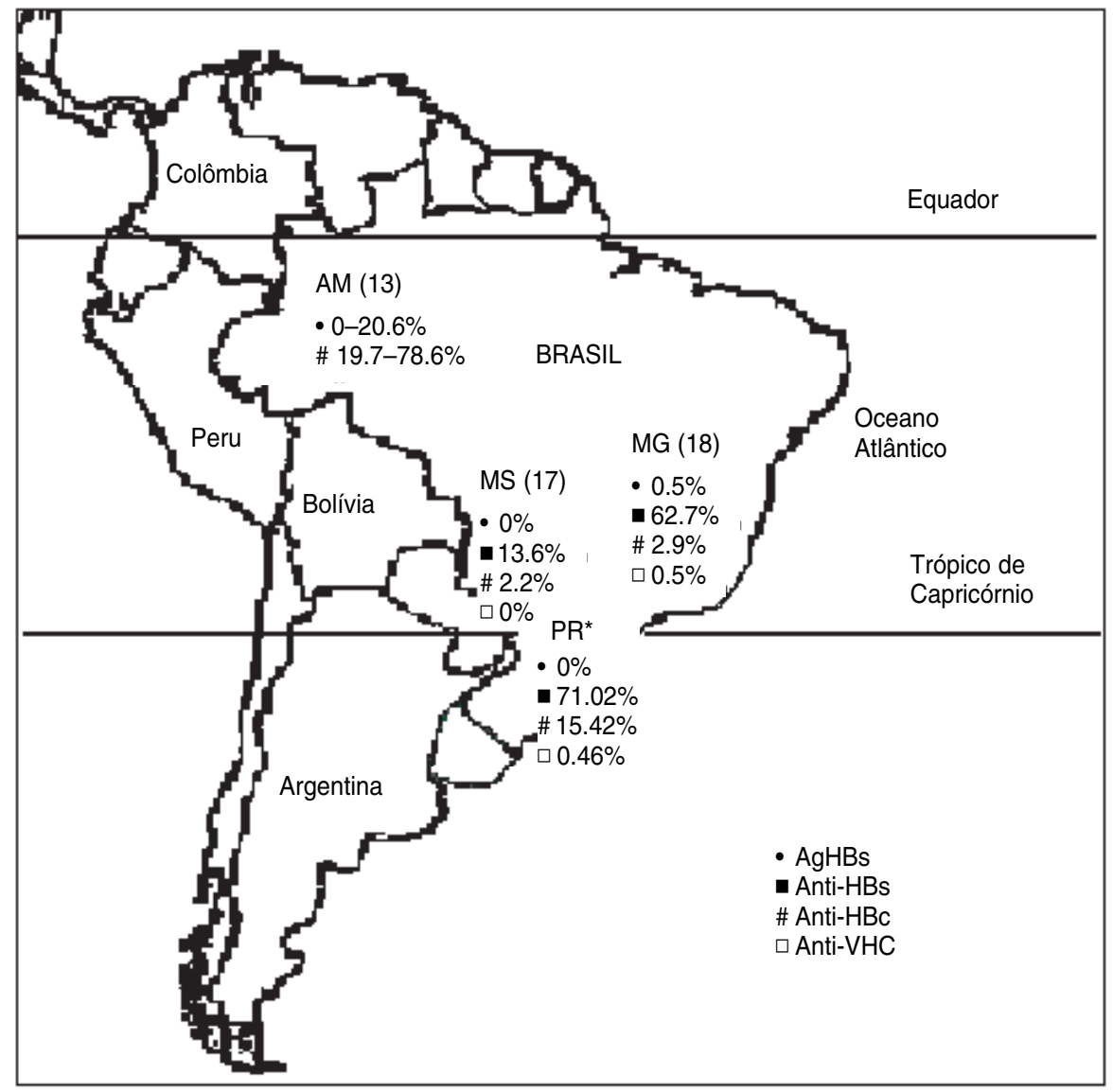

${ }^{\text {a }}$ AM = Amazonas; $M S=$ Mato Grosso do Sul; MG = Minas Gerais; PR = Paraná. *Presente estudo.

sileira é composta de 215 povos que falam 181 idiomas. A infecção pelo VHB é endêmica na América do Sul e sua prevalência é particularmente alta na Amazônia, inclusive entre as populações indígenas $(14,15,20,21)$.

De um modo geral, a infecção pelo VHB é considerada de alta endemicidade em regiões onde a prevalência do $\mathrm{AgHbs}$ é superior a $7 \%$ e mais de $60 \%$ da população têm evidência sorológica de infecção prévia. As áreas onde a prevalência do $A g H B s$ vai de 2 a $7 \%$ e a evidência sorológica da população está entre 20 e $60 \%$ são consideradas como de endemicidade intermediária. A endemicidade é considerada baixa nas áreas com uma prevalência do AgHBs menor do que $2 \%$ e de infecção prévia menor do que $10 \%$ (9). No Brasil, a Região Sul é tida como área de baixa ende- micidade, as regiões Centro-Oeste, Nordeste e Sudeste são de endemicidade intermediária e a Amazônia, o Estado do Espírito Santo e o Oeste de Santa Catarina são considerados de alta endemicidade para a infecção pelo VHB (9).

Os resultados deste estudo revelaram baixa prevalência de hepatite $B$ entre os indivíduos Kaingang investigados. A negatividade observada para o antígeno AgHbs indica a ausência de hepatite $B$ em atividade na população em estudo. A presença do marcador anti-HBc isolado em 1,87\% dos indivíduos sugere provável cicatriz sorológica, a qual foi confirmada pela negatividade de anticorpos anti-HBc IgM no soro desses indivíduos. Já a positividade concomitante dos anticorpos antiHBs e anti-HBc em 13,55\% das amostras indicam imunidade pós-hepatite B.
Por outro lado, a presença do marcador anti-HBs isolado em $57,47 \%$ dos indivíduos sugere imunidade adquirida pósvacina. Interessantemente, a positividade para anti-HBc apresentou-se de forma crescente em relação à idade, enquanto que a positividade para antiHBs foi inversamente proporcional à idade. A alta prevalência de anti-HBs isolado nas faixas etárias mais baixas indica que, na população jovem, a imunidade foi adquirida principalmente através de imunização por vacina, enquanto que $15,42 \%$ da população adulta adquiriram imunidade de forma ativa natural. Esses resultados demonstram que as estratégias de vacinação contra a hepatite $B$ estão sendo eficazes no controle da doença entre os indígenas dessa região. De fato, a vacina contra a hepatite B faz parte do calendário oficial de vacinação preconizado pelo Ministério da Saúde e atualmente o Estado do Paraná disponibiliza a mesma a todos os menores de 20 anos.

Com relação ao marcador para hepatite $C$, sua positividade foi observada em somente uma dona de casa com idade de 30 anos e história de icterícia. Essa senhora foi devidamente encaminhada para orientações e tratamento, através do serviço de saúde responsável pela reserva indígena. Além disso, o modo de infecção está sendo investigado. Há poucos estudos soroepidemiológicos sobre a prevalência de infecção pelo VHB ou VHC nas populações indígenas no Brasil, sendo que a maioria deles têm se concentrado em povos da Região Amazônica.

Ferraroni et al. estudaram a soropositividade de anticorpos contra o VHB em diferentes tribos amazônicas. A positividade para infecção pelo VHB foi de 1,3\% na tribo Mayongong, 20,2\% na tribo Mundurucu e 0,9\% na tribo Sanomã. Esses resultados demonstraram que a infecção pelo VHB foi menos prevalente em populações indígenas com menor contato com culturas nãoindígenas (16).

Já Coimbra et al., na investigação de dois grupos indígenas em quatro regiões amazônicas, encontraram alta positividade, com variação entre 62,8 e 95,7\%, para AgHBs, anti-HBs e anti- 
HBc. Esses autores sugeriram que tal resultado é decorrente de práticas culturais dessas populações, como incisão, escarificação, tatuagem e alimentos processados oralmente, que aumentam a probabilidade de transmissão do VHB (20).

No Oeste da Amazônia, Braga et al. avaliaram a presença dos marcadores sorológicos AgHBs, AgHBe, anti$\mathrm{HBc}$ total, anticorpo anti-HBc IgM e anti-Hbe em sete etnias indígenas: Apurinã, Kanamari, Deni, Jamamadi, Kulina, Mura-Pirahã e Paumari. Observou-se nesse estudo prevalência de infecção passada pelo VHB (positividade para anti-HBc) com variação entre as etnias de 19,7 a 78,6\%, média de $54,5 \%$ e positividade de portadores de AgHBs com variação de 0 a 20,6\%, com média de $9,7 \%$. Os resultados confirmaram o caráter endêmico da infecção pelo VHB na população estudada, apesar da distribuição heterogênea. Os autores sugerem que fatores como a densidade populacional, os aspectos genéticos, sociais, econômicos, culturais e históricos, além de outros desconhecidos, tenham influência na determinação dessa heterogeneidade (13).

Em outras regiões do Brasil, os estudos soroepidemiológicos evidenciam uma baixa prevalência de infecção por VHB e VHC entre povos indígenas. No Estado de Minas Gerais, Figueiredo et al. reportaram a prevalência de marcadores para VHB e VHC entre a população indígena Xacriabá. Essa população possui longa história de aculturação e contato com a sociedade moderna. Os autores encontraram positividade de 0,5\% para AgHBs, 2,9\% para anti-HBc, 62,7\% para anti-HBs e $0,5 \%$ para anti-VHC na população estudada. Os resultados indicam baixa prevalência de infecções por VHB e VHC e alta prevalência de vacinação prévia nessa comunidade (18).

No Mato Grosso do Sul, Aguiar et al. observaram baixa positividade tanto para os marcadores para VHB como para VHC em uma população indígena das reservas de Buriti, Córrego do Meio e Água Azul. Nenhum caso foi positivo para AgHBs ou para anti-VHC. Os anticorpos anti-HBc foram positivos em 2,2\% e os anti-HBs em $13,6 \%$ dos indivíduos. Os autores sugeriram que a positividade para anticorpos anti-HBs seria o resultado de imunidade adquirida artificialmente através de vacinação (17).

Em conclusão, os resultados obtidos no presente estudo estão de acordo com aqueles obtidos fora da Região Amazônica e indicam baixa prevalência de ambas as infecções, por VHB e VHC, na população indígena Kaingang de Mangueirinha, Estado do Paraná. Essa prevalência se assemelha à observada na população não-indígena da mesma região geográfica, como ocorre na Região Amazônica, onde a prevalência para essas infecções é semelhante entre a população não-indígena e as tribos com longo tempo de aculturação, enquanto aquelas que não sofreram aculturação e miscigenação revelam prevalência significativamente menor dessas infecções (20). Embora os fatores genéticos tenham importante papel na predisposição a infecções, Neel et al. já sugeriram que os índios não teriam maior susceptibilidade genética a epidemias do que as populações não indígenas (caucasianos), ao contrário do que supunham alguns geneticistas humanos e antropólogos (22). Portanto, a variação na prevalência de infecção por VHB e VHC em diferentes áreas geográficas e populações indígenas deve estar vinculada, principalmente, a fatores ambientais, geográficos e epidemiológicos, em especial o contato com populações circunvizinhas.

Agradecimentos. Os autores agradecem aos doutores Márcia Gil, da Secretaria de Saúde do Estado do Paraná, Célia Fagundes da Cruz e Sueli Nakatani, do Laboratório Central do Estado do Paraná, Chiu Yun Yu Braga, Darci Braga e Altair Ambrósio; ao acadêmico de medicina Luis Eduardo Durães Barboza; aos enfermeiros Rosângela Chimilouski Silla, Adão Emerson Silla e Neusa Mutzemberg; ao Cacique Valdir e à FUNASA e FUNAI, que possibilitaram a realização deste trabalho através de sua colaboração e apoio.

\section{REFERÊNCIAS}

1. Fundação Nacional dos Índios (FUNAI). Etnias indígenas. [site da Internet]. Disponível em: http://www.funai.gov.br/indios/fr conteudo.htm. Acessado em agosto de 2006.

2. Diehl EE. Health problems among the Kaingang (Xapeco Indigenous Reserve, Santa Catarina) and the health care system. Cad Saude Publica. 2001;17(2):439-45.

3. Utiyama SR, Guardiano J, Petzl-Erler ML, Mocelim V, de Messias-Reason IJ. Perfil de autoanticorpos em índios das tribos Kaingang e Guarani do Sul do Brasil. Rev Panam Salud Publica. 2000;7(6):371-6.

4. Echevarría JM, León P. Epidemiology of viruses causing chronic hepatitis among populations from the Amazon Basin and related ecosystems. Cad Saude Publica. 2003;19(6): 1583-1591.
5. World Health Organization. Prevention and control of hepatitis B in the community. WHO Communicable Disease Series. 1996;1:17-26.

6. Maynard JE. Hepatitis B global importance and need for control. Vaccine. 1990;8(suppl): S18-20.

7. Zuckerman AJ. Hepatitis. Em: Cox FEG, ed. Illustrated history of tropical diseases. Londres: The Welcome Trust; 1996.

8. Cotran RS, Kumar V, Collins T. Patologia estrutural e funcional. $6^{\mathrm{a}}$ ed. Rio de Janeiro: Guanabara Koogan; 2000.

9. Chávez JH, Campana SG, Haas P. Panorama da hepatite B no Brasil e no Estado de Santa Catarina. Rev Panam Salud Publica. 2003; 14(2):91-6.

10. Miranda ECBM, Moia LJP, Amaral ISA, Barbosa MSB, Conde SRSS, Araújo MTFA, et al. In- feç̧ões pelos vírus das hepatites $\mathrm{B}$ e C e o carcinoma hepatocelular na Amazônia oriental. Rev Soc Bras Med Trop. 2004;37(supl 2): 47-51.

11. Fonseca JCF, Brasil LM. Infecção pelo vírus da hepatite $C$ na região Amazônica brasileira. Rev Soc Bras Med Trop. 2004;37(supl 2):1-7.

12. Programa Nacional para a prevenção e o controle das hepatites virais. Secretaria de Vigilância em Saúde. Ministério da Saúde Disponível em: www.portaldeginecologia. com.br/pdf/01/01.pdf. Acessado em agosto de 2006.

13. Braga WSM, Brasil LM, de Souza RAB, de Castilho MC, da Fonseca JCF. Ocorrência da infecção pelo vírus da hepatite B (VHB) e delta (VHD) em sete grupos indígenas do Estado do Amazonas. Rev Soc Bras Med Trop. 2001;34(4):349-55. 
14. Ferrari JO, Ferreira MU, Tanaka A, Mizokami $\mathrm{M}$. The seroprevalence of hepatitis $\mathrm{B}$ and $\mathrm{C}$ in an Amerindian population in the southwestern Brazilian Amazon. Rev Soc Bras Med Trop. 1999;32(3):299-302.

15. Azevedo RA, Silva AE, Ferraz MLG, Marcopito LF, Baruzzi RG. Prevalência dos marcadores sorológicos dos vírus da hepatite B e D em crianças das tribos Caiabi e Txucarramãe do Parque Indígena do Xingu, Brasil, Central. Rev Soc Bras Med Trop. 1996;29(5): 431-9.

16. Ferraroni JJ, Lacaz CS. Prevalência de anticorpos contra os agentes causadores da hepatite, malária, sífilis e toxoplasmose em cinco populações humanas distintas da Amazônia brasileira. Rev Inst Med Trop Sao Paulo. 1982; 24(3):155-61.
17. Aguiar JI, Souza JA, Aguiar ES, Oliveira JM, de Lemos ER, Yoshida CF. Low prevalence of hepatitis $B$ and $C$ markers in non-Amazonian indigenous population. Braz J Infect Dis. 2002; 6(5):269-70.

18. Figueiredo JFC, Machado AA, Martinez R. Prevalências das infecções pelos vírus das hepatites B e C na Reserva Indígena Xacriabá, MG, Brasil. Rev Soc Bras Med Trop. 2000; 33(supl 1):211.

19. Terras indígenas do Paraná. Disponível em: www.achetudoregiao.com.br/PR/indigenas parana.htm. Acessado em agosto de 2006.

20. Coimbra Jr CE, Santos RV, Yoshida CF, Baptista ML, Flowers NM, do Valle AC. Hepatitis B epidemiology and cultural practices in Amerindian populations of Amazonia: the Tupi-
Monde and the Xavante from Brazil. Soc Sci Med. 1996:42(12):1735-43.

21. Braga WSM. Infecção pelos vírus das hepatites $\mathrm{B}$ e D entre grupos indígenas da Amazônia Brasileira: aspectos epidemiológicos. Rev Soc Bras Med Trop. 2004;37(supl 2): 9-13.

22. Neel JV, Centerwall WR, Chagnon NA, Casey HL. Notes on the effect of measles and measles vaccine in a virgin-soil population of South American Indians. Am J Epidemiol. 1970;91(4):418-29.

Manuscrito recebido em 28 de junho de 2005. Aceito em versão revisada em 20 de junho de 2006.

ABSTRACT Objective. To investigate the prevalence of infection with hepatitis B virus (HBV) and hepatitis $\mathrm{C}$ virus (HCV) among Kaingang Indians living on the Mangueirinha reservation in the state of Paraná, Brazil.

\section{Seroepidemiology of hepatitis $B$ and $C$ in Kaingang Indians in the South of Brazil}

Methods. The presence of viral markers was investigated in blood samples from 214 volunteers (81 males, 133 females), using immunoenzymatic techniques. The viral markers studied were: antibody to hepatitis B core antigen (anti- $\mathrm{HB}_{\mathrm{c}}$ ), antibody to hepatitis B surface antigen $\left(\right.$ anti- $\left.\mathrm{HB}_{\mathrm{s}}\right)$, hepatitis B surface antigen $\left(\mathrm{HB}_{\mathrm{s}} \mathrm{Ag}\right)$, and antibody to hepatitis $\mathrm{C}$ virus (anti-HCV). The participants answered a questionnaire on their sociodemographic characteristics, living conditions, personal habits (such as smoking and consuming alcohol or illicit drugs), and history of disease and of vaccination.

Results. The respondents ranged in age from 1 to 90 years; their mean age was 29.85 years. Positivity for anti- $\mathrm{HB}_{\mathrm{s}}$ was $71.02 \%$, and for anti- $\mathrm{HB}_{\mathrm{c}}$ it was $15.42 \%$. None of the individuals was positive for $\mathrm{HB}_{\mathrm{s}} \mathrm{Ag}$. Anti-HCV was detected in only one participant, a 30-year-old woman.

Conclusions. There were low prevalences of HBV and HCV infection in the Kaingang population studied. The high prevalence of anti- $\mathrm{HB}_{\mathrm{s}}$ in younger individuals indicates good immunization coverage. In the adult population, immunity against HBV was probably acquired mainly by contact with the virus.

Key words Hepatitis B; hepatitis C; Indians, South American; Brazil.

\section{Errata}

\section{Robilotta, "A tomografia por emissão de pósitrons: uma nova modalidade na medicina nuclear brasileira"} (Rev Panam Salud Publica. 2006;20(2/3):134-42.)

Na página 141 da versão impressa foi omitida a seguinte nota, publicada corretamente na versão eletrônica disponível em http:// journal.paho.org/uploads/1162234592.pdf:

2 Em fevereiro de 2006, o Congresso Nacional Brasileiro promulgou uma emenda constitucional que flexibilizou a produção de radionuclídeos de meia-vida curta, tornando possível a produção de nuclídeos como o flúor-18, o carbono-11 e o oxigênio-15 por instalações que não estejam subordinadas à CNEN, mas dentro das normas estabelecidas por ela. 0 número de equipamentos dedicados a estudos de PET, tomógrafos PET e PET/CT totaliza 12 em todo território nacional e tende a aumentar num futuro próximo, com a possibilidade de instalação de cíclotrons para a produção de FDG marcada com flúor-18.

A nota se refere à afirmação constante no topo da segunda coluna da página 141 de que só duas instituições no Brasil produzem 0 radiofármaco $\left({ }^{18} \mathrm{~F}\right)$ FDG, o Instituto de Pesquisa em Energia Nuclear em São Paulo e o Instituto de Engenharia Nuclear no Rio de Janeiro. 